\title{
Metabolism of very low- and low-density lipoproteins isolated from normolipidaemic Type 2 (non-insulin-dependent) diabetic patients by human monocyte-derived macrophages
}

\author{
R. L. Klein ${ }^{1,2}$, T.J.Lyons ${ }^{2}$ and M.F.Lopes-Virella ${ }^{1,2}$ \\ ${ }^{1}$ Research Service, Veterans Administration Medical Center, and \\ ${ }^{2}$ Department of Medicine, Medical University of South Carolina, Charleston, South Carolina, USA
}

\begin{abstract}
Summary. The very low- and low-density lipoprotein fractions were isolated from 16 normolipidaemic Type 2 (non-insulin-dependent) diabetic patients in good to fair glycaemic control and from corresponding age-, sex-, and racematched, non-diabetic control subjects. Rates of cholesteryl ester synthesis averaged $268 \pm 31$ vs $289 \pm 40 \mathrm{pmol}{ }^{14} \mathrm{C}$-cholesteryl oleate $\cdot \mathrm{mg}$ cell protein ${ }^{-1} \cdot 20 \mathrm{~h}^{-1}$ for very low- and $506 \pm 34$ vs $556 \pm 51 \mathrm{pmol}{ }^{14} \mathrm{C}$-cholesteryl oleate $\cdot \mathrm{mg}$ cell protein $^{-1} \cdot 20 \mathrm{~h}^{-1}$ for low-density lipoproteins isolated from the Type 2 diabetic patients and control subjects, respectively, when they were incubated with human macrophages. A group of approximately one-third of the patients was selected for separate analyses because very low-density lipoproteins isolated from these patients did stimulate more cholesteryl ester synthesis when incubated with macrophages. There were no significant differences in the lipid composition of the lipoproteins isolated from the three groups of subjects. The relative proportion of apoprotein $\mathrm{C}$ to apoprotein $\mathrm{E}$ was sig-
\end{abstract}

nificantly decreased $(p<0.002)$ in the very low-density lipoproteins from diabetic patients and was further decreased in samples from these selected diabetic patients. The apoprotein C-I content of very low-density lipoproteins isolated from diabetic patients was increased compared to control subjects and was further increased in samples from the selected diabetic patients $(p<0.02)$. There were no significant differences in the proportions of apoproteins C-III-0, C-III1, or C-III-2 among the three groups. These studies suggest that in normolipidaemic Type 2 diabetic patients, the apoprotein composition of VLDL is abnormal and this may alter VLDL macrophage interactions and thus contribute to the increased prevalence of atherosclerosis in diabetic patients.

Key words: Type 2 (non-insulin-dependent) diabetes mellitus, VLDL metabolism, LDL metabolism, human macrophages.
There is an increased prevalence of atherosclerosis in patients with diabetes mellitus, and vascular disease accounts for $70-80 \%$ of the deaths in diabetic patients [1-3]. It is known that for similar lipid levels, the morbidity and mortality is higher in diabetic than in non-diabetic subjects. Thus, factors other than quantitative alterations of lipid and lipoprotein concentrations are important in the acceleration of atherosclerosis in diabetes. Recently, several studies have investigated the metabolism of lipoproteins isolated from diabetic patients with cells involved in the atherosclerosis process to determine if altered lipoprotein-cell interactions contribute to increased atherogenesis in diabetic patients.

The catabolism by human fibroblasts of low-density lipoproteins (LDL) isolated from Type 1 (insulin-dependent) diabetic patients is impaired [4], while studies using LDL isolated from Type 2 (non-insulin-dependent) diabetic patients have not documented any abnormality in LDL catabolism by fibroblasts except in patients who were markedly hypertriglyceridaemic $[5,6]$. Both triglyceride enrichment $[5,6]$ and glycosylation [7-12] of the
LDL particle have been implicated in the impaired recognition of LDL by cell lipoprotein receptors. In addition, when very low-density lipoproteins (VLDL) were glycosylated in vitro and incubated with fibroblasts, VLDL catabolism was significantly reduced [13].

Macrophages, however, are thought to be the main precursors of the cholesterol-laden foam cells characteristic of the atheromatous lesion. We have shown recently that LDL glycosylated in vitro [14] and LDL isolated from Type 1 diabetic patients in fair to good glycaemic control [15] stimulate cholesteryl ester synthesis and accumulation in human macrophages. In contrast, studies performed in mouse peritoneal macrophages showed that the rates of degradation of LDL glycosylated in vitro [8,9] or isolated from Type 2 diabetic patients [5] were not significantly faster than that of native LDL.

VLDL isolated from Type 1 diabetic patients in fair to good glycaemic control stimulate cholesteryl ester synthesis and accumulation in human macrophages [16] and VLDL isolated from Type 2 diabetic patients are also taken up more avidly by mouse peritoneal macrophages 
Table 1. Clinical characteristics of Type 2 (non-insulin-dependent) diabetic and control groups

\begin{tabular}{|c|c|c|c|c|c|c|}
\hline Group $^{a}$ & $\begin{array}{l}\text { Sex } \\
\text { (male:female) }\end{array}$ & $\begin{array}{l}\text { Race } \\
\text { (black:white) }\end{array}$ & $\begin{array}{l}\text { Age } \\
\text { (years) }\end{array}$ & $\begin{array}{l}\text { Body } \\
\text { mass index }\end{array}$ & $\begin{array}{l}\text { Duration of } \\
\text { diabetes (years) }\end{array}$ & $\begin{array}{l}\text { Diabetes } \\
\text { treatment }(\mathrm{D}: \mathrm{O}: \mathrm{I})\end{array}$ \\
\hline Control & $13: 3$ & $2: 14$ & $\begin{array}{c}56.5 \pm 2.6^{b} \\
(36-73)\end{array}$ & $\begin{array}{c}25.8 \pm 1.0 \\
(21.2-35.6)\end{array}$ & - & - \\
\hline Diabetic & $8: 3$ & $2: 9$ & $\begin{array}{r}55.0 \pm 2.9 \\
(38-68)\end{array}$ & $\begin{array}{c}28.9 \pm 1.1 \\
(21.7-36.8)\end{array}$ & $\begin{array}{r}7.2 \pm 2.3 \\
(1-23)\end{array}$ & $4: 5: 2$ \\
\hline $\begin{array}{l}\text { Selected } \\
\text { diabetic }\end{array}$ & $5: 0$ & 0.5 & $\begin{array}{r}57.3 \pm 2.1 \\
(52-61)\end{array}$ & $\begin{array}{c}29.3 \pm 1.4 \\
(22.0-35.1)\end{array}$ & $\begin{array}{r}10.5 \pm 9.5 \\
(1-20)\end{array}$ & $2: 2: 1$ \\
\hline
\end{tabular}

a Data for control group derived from all non-diabetic subjects. Diabetic group is composed of those patients whose VLDL did not stimulate more cholesteryl ester synthesis in human macrophages. Selected diabetic group composed of those patients whose VLDL did stimulate more cholesteryl ester synthesis in macrophages. ${ }^{b}$ Values shown are mean \pm SEM and (range) for each group. ${ }^{c}$ Type of treatment regimen followed to maintain glycaemic control: $\mathrm{D}$, diet only; $\mathrm{O}$, oral hypoglycaemic agents; $\mathrm{I}$, insulin

[17]. No studies have investigated, however, the interaction of VLDL or LDL isolated from normolipidaemic, Type 2 diabetic patients with human monocyte-derived macrophages. Therefore, we decided to investigate whether VLDL and LDL isolated from normolipidaemic, Type 2 diabetic patients in good to fair glycaemic control would interact abnormally with human macrophages and whether that abnormal interaction, if present, results from an altered composition of the VLDL and LDL due to the diabetic state.

\section{Subjects and methods}

\section{Subjects}

Sixteen patients with Type 2 diabetes were recruited from the Private Diagnostic Clinic of the Medical University of South Carolina and were diagnosed according to the criteria established by the $\mathrm{Na}$ tional Diabetes Data Group [18]. For every diabetic patient, an age-, sex-, and race-matched, non-diabetic control subject was recruited and blood was drawn on the same day from each member of the matched pair. Only normolipidaemic subjects were accepted for inclusion in the study in order to exclude the potentially confounding effects of hypertriglyceridaemia on cell-lipoprotein interactions.

Three patients had evidence of background retinopathy while none had proteinuria. One patient was taking a $\beta$-blocker, one, digoxin, and three, nitrates. Two patients and one control subject were taking aspirin. Two patients reported having had a myocardial infarct more than six months prior to the study. No participants were receiving hypolipidaemic medications. The diabetic patients were treated by diet $(n=6)$, oral hypoglycaemic agents (no biguanides) $(n=7)$ or insulin $(n=3)$. Additional clinical characteristics and the parameters of glycaemic control and plasma lipid levels of the diabetic and control groups are shown in Tables 1 and 2, respectively. Informed consent, as approved by the Institutional Review Board of the Medical University of South Carolina, was obtained from all subjects involved in the study.

\section{Protocol}

A $60 \mathrm{ml}$ sample of blood was collected in ethylenediaminetetraacetic acid (EDTA) $(1 \mathrm{mg} / \mathrm{ml}$ blood) from all subjects after a 12-14 $\mathrm{h}$ fast. This sample was used to isolate VLDL and LDL for metabolic studies and for the determination of lipoprotein composition. Cholesteryl ester (CE) synthesis was measured in human monocytederived macrophages incubated with the VLDL or LDL from the diabetic and respective control subjects. For each experiment, the monocytes used were obtained from an individual, non-diabetic donor. Different donors were used for different experiments. Matched samples from diabetic and control subjects were always studied in the same experiment and each sample was incubated in duplicate. The lipid composition (free and esterified cholesterol, triglycerides and phospholipids) and apoprotein composition were determined for each lipoprotein sample. Fasting plasma glucose concentration, $\mathrm{HbA}_{\mathrm{IC}}$ level, fasting lipid profiles and the extent of glycosylation of serum proteins and LDL were determined for each subject.

\section{Monocyte isolation and maturation}

Monocytes were isolated from leukapheresis specimens by countercurrent centrifugal elutriation $[19,20]$. The purity of the monocyte preparations was found to be $93 \%$ by checking morphology on Wright's stained cytocentrifuge preparations, $92 \%$ by non-specific

Table 2. Parameters of glycaemic control and plasma lipid levels in Type 2 (non-insulin-dependent) diabetic and control groups

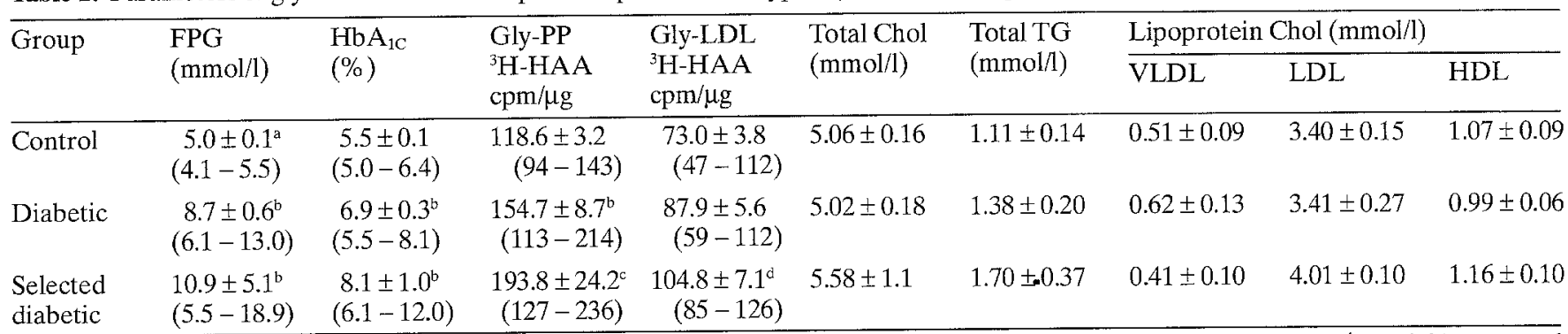

a Values shown are mean \pm SEM and (range) for each group. ${ }^{\mathrm{b}} p<0.001$ vs control group; ${ }^{\circ} p<0.005$ vs control group; ${ }^{\mathrm{d}} p<0.01$ vs control group.

FPG - fasting plasma glucose; Gly-PP - glycosylated plasma proteins; Gly-LDL - glycosylated LDL; ${ }^{3} \mathrm{H}-\mathrm{HAA}$ - tritiated hexitol amino acids; Chol-cholesterol; TG-triglycerides 
esterase staining and $93 \%$ by observing their ability to ingest latex particles [21]. The average viability of the cells was $99 \%$. The isolated monocytes were matured by incubation at $37^{\circ} \mathrm{C}$ for eight days in a humidified incubator with a $5 \% \mathrm{CO}_{2}$ atmosphere. The medium used to induce maturation was a supplemented Iscove's modified Dulbecco's medium (IMDM) containing 30\% volume/volume (V/V) of whole human serum (Whittaker MA Bioproducts, Walkersville, Md., USA) as described previously [14].

\section{Lipoprotein isolation and composition}

VLDL (density $=\mathrm{d} ; \mathrm{d}<1.006 \mathrm{~g} / \mathrm{ml}$ ) were isolated from plasma at $10^{\circ} \mathrm{C}$ by ultracentrifugation at $60000 \mathrm{rev} / \mathrm{min}$ for $18 \mathrm{~h}$ in a Beckman 60 Ti rotor (Beckman Instruments, Inc, Palo Alto, Calif., USA). The floating VLDL were removed after tube-slicing and washed and concentrated by ultracentrifugation at their isolation density at $10^{\circ} \mathrm{C}$ in a SW41 rotor (Beckman Instruments, Inc), spun at $40000 \mathrm{rev} / \mathrm{min}$ for $24 \mathrm{~h}$. The LDL fraction $(1.019<\mathrm{d}<1.063 \mathrm{~g} / \mathrm{ml})$ was isolated after preliminary ultracentrifugation of the $\mathrm{d}>1.006 \mathrm{~g} / \mathrm{ml}$ plasma fraction at $\mathrm{d}=1.019 \mathrm{~g} / \mathrm{ml}$. The floating intermediate density lipoprotein fraction (IDL) was discarded and the plasma solvent density was increased to $d=1.063 \mathrm{~g} / \mathrm{ml}$. LDL was isolated by tube-slicing after ultracentrifugation at $60000 \mathrm{rev} / \mathrm{min}$ at $10^{\circ} \mathrm{C}$ for $22 \mathrm{~h}$. The isolated LDL solution was washed and concentrated by centrifugation in a SW41 rotor as described above. The isolated and washed VLDL and LDL were dialyzed against saline $(0.9 \% \mathrm{NaCl}, 0.01 \%$ weight/volume (W/V) EDTA, pH 7.4). Salt solutions used to adjust solvent densities also contained $0.1 \%$ (W/V) EDTA, pH 7.4. The dialysed lipoprotein solutions were sterilized by passage through a $0.2 \mu \mathrm{m}$ filter (Gelman Sciences, Ann Arbor, Mich., USA) and stored at $4^{\circ} \mathrm{C}$.

\section{Lipoprotein composition analysis}

Samples of the isolated lipoprotein fractions were extracted with chloroform/methanol $(2: 1, \mathrm{~V} / \mathrm{V})[22]$. The free and total cholesterol [23], triglyceride [24], phospholipid phosphorus [25], and protein [26] concentrations of the lipoprotein samples were determined as described previously [14].

The apoprotein composition of VLDL isolated from both groups was examined using quantitative immunoelectrophoresis and analytical isoelectric focussing (IEF). VLDL apoprotein B concentration was determined using quantitative immunoelectrophoresis with LDL $(1.030<\mathrm{d}<1.050)$ used as the standard [27]. The relative proportions of apoprotein $\mathrm{E}$ and apoprotein $\mathrm{C}$ were estimated by densitometric scanning of VLDL apoproteins separated by IEF using $7.5 \%$ polyacrylamide gels containing $2 \%$ ampholine, $\mathrm{pH} 4-6$ [2830]. The relative proportions of the apoproteins were determined by scanning densitometry at $580 \mathrm{~nm}$ in a Beckman scanning densitometer (Beckman Instruments, Inc). Densitometric scanning was validated and its reproducibility was assessed by the scanning linearity observed with gels loaded with different amounts of protein. The concentrations of apoprotein $\mathrm{E}$ and $\mathrm{C}$ in VLDL were estimated using the following calculations. The concentration of nonapoprotein B proteins was calculated as the difference between total VLDL protein concentration and the concentration of apoprotein B determined by quantitative immunoelectrophoresis. The relative concentrations of apoprotein $E$ and $C$ were estimated by distributing the concentration of the non-apoprotein $\mathrm{B}$ proteins in VLDL in proportion to the relative densitometric areas of apoproteins $\mathrm{E}$ and $\mathrm{C}$ in the IEF gels. No compensation was made for the differential chromogenicity of apoprotein C-II $[31,32]$

\section{Incorporation of $\left[1-{ }^{14} \mathrm{C}\right]$-oleate into cholesteryl esters}

Cholesteryl ester synthesis was determined after incubation of monocyte-derived macrophages for $20 \mathrm{~h}$, at $37^{\circ} \mathrm{C}$ with serum-free medium containing $0.2 \mathrm{mmol}{ }^{14} \mathrm{C}$-oleate $/ 2.5 \mathrm{mg}$ of bovine serum albumin [ $4 j$ and $100 \mu \mathrm{g}$ of VLDL or LDL isolated from diabetic and respective control subjects. The cells were incubated for $20 \mathrm{~h}$ at $37^{\circ} \mathrm{C}$ and were harvested with a rubber policeman using $1 \mathrm{ml}$ of phosphate-buffered saline and rinsed with $2 \mathrm{ml}$ of the same solution. Lipids in the cell pellet were extracted with chloroform/methanol $(2: 1)(\mathrm{V} / \mathrm{V})[22]$. Cholesteryl- $\left[{ }^{14} \mathrm{C}\right]$-oleate was isolated by thin layer chromatography of the lipid extracts on silica gel plates developed in a solvent system of petroleum ether/ethyl ether/acetic acid (80:20:2) $(\mathrm{V} / \mathrm{V} / \mathrm{V})$. Lipids were visualized with $\mathrm{I}_{2}$ vapour, and the spots which co-migrated with a cholesteryl oleate standard were marked and scraped into scintillation vials after the total disappearance of colour. Scintillation fluid (ScintiPrep, Fisher Scientific Co, Fairlawn, NJ, USA), was added and the samples counted in a liquid scintillation counter. Correction for procedural losses was made by adding ${ }^{3} \mathrm{H}-$ cholesteryl oleate as an internal standard to the chloroform/methanol extraction mixture. After the lipid extraction, the cell pellet was solubilized with $1 \mathrm{~mol} / \mathrm{L} \mathrm{NaOH}$ and the protein content determined [26].

\section{Measurement of glycosylation of $L D L$}

Glycosylation of LDL was determined by affinity chromatography as described previously [33]. Stored LDL samples were thawed and aggregated lipoproteins were dispersed by brief $(<5 \mathrm{~s})$ sonication (Probe sonicator, Heat Systems-Ultrasonic Inc, Plainview, NY, USA) before assessing their degree of glycosylation. In every case both members of a diabetic-control pair were studied in the same experiment, and the same batch of tritiated sodium borohydride was used throughout.

\section{Other methods}

Plasma glucose was assayed by the glucose oxidase method, as adapted for use in the Beckman glucose analyser [34]. $\mathrm{Hb}_{\mathrm{IC}}$ was measured by IEF of erythrocyte haemolysates in a gradient of $\mathrm{pH}$ 6-8 [35]. Plasma HDL cholesterol concentration was determined after precipitating VLDL and LDL with sodium phosphotungstate/magnesium chloride as described [36]. Total cholesterol and triglyceride were measured in whole plasma and lipoprotein fractions by the semi-automated methods standardized by the Lipid Research Clinics Program [24].

\section{Statistical analysis}

Data from paired observations was analysed with the Wilcoxon signed-rank test. Group data from non-paired observations was analysed with the Mann-Whitney $U$ test. These analyses, as well as other correlation analyses, were determined with the Stat View $\mathrm{SE}+$ Graphics statistical package (Abacus Concepts, Berkeley, Calif., USA).

\section{Results}

There were no significant differences in the rates of cholesteryl ester synthesis in human macrophages incubated with VLDL or LDL isolated from hyperglycaemic, normolipidaemic, Type 2 diabetic patients compared with the same lipoprotein fractions isolated from their respective non-diabetic, control subjects. Rates of cholesteryl ester synthesis in human macrophages incubated with VLDL isolated from Type 2 diabetic patients and control subjects averaged $268 \pm 31$ and $289 \pm 40 \mathrm{pmol}{ }^{14} \mathrm{C}$-cholesteryl oleate synthesized $\cdot \mathrm{mg}$ cell protein ${ }^{-1} \cdot 20 \mathrm{~h}^{-1}$ (mean \pm SEM), respectively. Rates of cholesteryl ester synthe- 
Table 3. Chemical composition of VLDL and LDL isolated from Type 2 (non-insulin-dependent) diabetic patients and control subjects

\begin{tabular}{llrrrr}
\hline Lipoprotein & Group & \multicolumn{4}{c}{ Ratio of constituents (mg/mg) } \\
\cline { 3 - 6 } & & TC/Pro & FC/Pro & CE/Pro & TG/Pro \\
\hline VLDL & Control & $1.23^{\mathrm{a}}$ & 0.57 & 1.12 & 7.11 \\
& \pm 0.10 & \pm 0.05 & \pm 0.11 & \pm 1.51 \\
& Diabetic & 1.11 & 0.54 & 0.97 & 6.34 \\
& \pm 0.09 & \pm 0.04 & \pm 0.10 & \pm 0.49 \\
& Selected & 1.36 & 0.63 & 1.24 & 6.69 \\
& diabetic & \pm 0.18 & \pm 0.06 & \pm 0.28 & \pm 0.37 \\
LDL & Control & 1.87 & 0.49 & 2.36 & 0.43 \\
& & \pm 0.05 & \pm 0.01 & \pm 0.06 & \pm 0.05 \\
& Diabetic & 1.83 & 0.48 & 2.31 & 0.38 \\
& \pm 0.03 & \pm 0.09 & \pm 0.06 & \pm 0.06 \\
\hline
\end{tabular}

a Values are shown as mean \pm SEM.

TC, total cholesterol; Pro, protein; FC, free cholesterol; $\mathrm{CE}$, cholesteryl ester $=1.7 \times$ esterified cholesterol; $\mathrm{TG}$, triglyceride

Table 4. Apoprotein composition of VLDL isolated from control subjects and Type 2 (non-insulin-dependent) diabetic patients

\begin{tabular}{|c|c|c|c|c|c|c|}
\hline \multirow[b]{2}{*}{ Group $^{a}$} & \multicolumn{3}{|l|}{$\%$} & \multicolumn{3}{|c|}{ Ratio of constituents } \\
\hline & Apo B & Apo $\mathrm{E}$ & Apo C & $\mathrm{B} / \mathrm{E}$ & $\mathrm{B} / \mathrm{C}$ & $\mathrm{C} / \mathrm{E}$ \\
\hline Control & $\begin{array}{c}51.0 \\
\pm 1.4^{\mathrm{b}}\end{array}$ & $\begin{array}{r}15.5 \\
\pm 1.0\end{array}$ & $\begin{array}{r}33.4 \\
\pm 1.0\end{array}$ & $\begin{array}{r}3.50 \\
\pm 0.28\end{array}$ & $\begin{array}{r}1.57 \\
\pm 0.09\end{array}$ & $\begin{array}{r}2.21 \\
\pm 0.10\end{array}$ \\
\hline Diabetic & $\begin{array}{r}48.8 \\
\pm 3.0\end{array}$ & $\begin{array}{r}17.6 \\
\pm 1.1\end{array}$ & $\begin{array}{r}33.6 \\
\pm 2.5\end{array}$ & $\begin{array}{r}2.84 \\
\pm 0.29\end{array}$ & $\begin{array}{r}1.52 \\
\pm 0.21\end{array}$ & $\begin{array}{r}1.93 \\
\pm 0.19^{\circ}\end{array}$ \\
\hline $\begin{array}{l}\text { Selected } \\
\text { diabetic }\end{array}$ & $\begin{array}{r}52.1 \\
\pm 2.1\end{array}$ & $\begin{array}{r}18.1 \\
\pm 1.3\end{array}$ & $\begin{array}{r}29.8 \\
\pm 1.5\end{array}$ & $\begin{array}{r}3.09 \\
\pm 0.28\end{array}$ & $\begin{array}{r}1.84 \\
\pm 0.18\end{array}$ & $\begin{array}{r}1.70 \\
\pm 0.11\end{array}$ \\
\hline
\end{tabular}

a Data for control group resulted from analyses of VLDL from 11 control subjects from whom sufficient material was available for analysis. Diabetic subjects are those patients whose VLDL did not stimulate more cholesteryl ester synthesis than VLDL from nondiabetic control subjects when incubated with human macrophages. Selected diabetic subjects are the five diabetic patients whose VLDL did stimulate more cholesteryl ester synthesis when incubated with macrophages. ${ }^{b}$ Values are shown as mean \pm SEM. ${ }^{c} p<0.002$ vs control subjects.

Apo B, apolipoprotein B; Apo E, apolipoprotein E; Apo C, apolipoprotein $\mathrm{C}$; $\mathrm{B} / \mathrm{E}$, apolipoprotein $\mathrm{B}$ mass $\div$ apolipoprotein $\mathrm{E}$ mass; $\mathrm{B} / \mathrm{C}$, apolipoprotein $\mathrm{B}$ mass $\div$ apolipoprotein $\mathrm{C}$ mass; $\mathrm{C} / \mathrm{E}$, apolipoprotein $\mathrm{C}$ mass $\div$ apolipoprotein $\mathrm{E}$ mass

Table 5. Apoprotein C composition of VLDL isolated from control subjects and Type 2 (non-insulin-dependent) diabetic patients

\begin{tabular}{|c|c|c|c|c|c|c|}
\hline \multirow[b]{2}{*}{ Group } & \multicolumn{3}{|c|}{$\begin{array}{l}\% \text { of apoprotein C } \\
\text { densitometric area }\end{array}$} & \multicolumn{3}{|c|}{ Ratio of areas } \\
\hline & C-I & C-II & $\overline{\mathrm{C}-\mathrm{III}}$ & $\mathrm{C}-\mathrm{II} / \mathrm{C}-\mathrm{I}$ & C-III/C-I & C-III/C-II \\
\hline Control & $\begin{array}{r}9.9 \\
\pm 1.1^{\mathrm{a}}\end{array}$ & $\begin{array}{r}17.0 \\
\pm 0.8\end{array}$ & $\begin{array}{r}73.4 \\
\pm 0.9\end{array}$ & $\begin{array}{r}2.0 \\
\pm 0.3\end{array}$ & $\begin{array}{r}8.4 \\
\pm 0.9\end{array}$ & $\begin{array}{r}4.5 \\
\pm 0.3\end{array}$ \\
\hline Diabetic & $\begin{array}{r}10.9 \\
\pm 1.4\end{array}$ & $\begin{array}{r}18.8 \\
\pm 0.7\end{array}$ & $\begin{array}{r}72.3 \\
\pm 1.9\end{array}$ & $\begin{array}{r}2.0 \\
\pm 0.4\end{array}$ & $\begin{array}{r}7.4 \\
\pm 1.0\end{array}$ & $\begin{array}{r}3.9 \\
\pm 0.3\end{array}$ \\
\hline $\begin{array}{l}\text { Selected } \\
\text { diabetic }\end{array}$ & $\begin{array}{l}16.5 \\
\pm 3.1^{\mathrm{b}}\end{array}$ & $\begin{array}{r}16.8 \\
\pm 1.6 \\
\end{array}$ & $\begin{array}{r}66.7 \\
\pm 3.1^{c} \\
\end{array}$ & $\begin{array}{r}1.3 \\
\pm 0.3\end{array}$ & $\begin{array}{r}5.2 \\
\pm 1.6^{\mathrm{d}} \\
\end{array}$ & $\begin{array}{r}4.1 \\
\pm 0.4 \\
\end{array}$ \\
\hline \multicolumn{7}{|c|}{$\begin{array}{l}\text { Values are shown as mean } \pm \text { SEM. }{ }^{b} p<0.02 \text { vs control subjects; } \\
{ }^{c} p=0.059 \text { vs control subjects; }{ }^{\mathrm{d}} p<0.05 \text { vs control subjects. } \\
\text { C-I, apolipoprotein C-I; C-II, apolipoprotein C-II; C-III apolipo- } \\
\text { protein C-III; C-II/C-I, apolipoprotein C-II mass } \div \text { apolipoprotein } \\
\text { C-I mass; C-III/C-I, apolipoprotein C-III mass } \div \text { apolipoprotein } \\
\text { C-I mass; C-III/C-II, apolipoprotein C-III mass } \div \text { apolipoprotein } \\
\text { C-II mass }\end{array}$} \\
\hline
\end{tabular}

sis averaged $506 \pm 34$ and $556 \pm 51$ pmol ${ }^{14} \mathrm{C}$-cholesteryl oleate $\cdot \mathrm{mg}$ cell protein ${ }^{-1} \cdot 20 \mathrm{~h}^{-1}$ when macrophages were incubated with LDL isolated from the Type 2 diabetic and control groups, respectively. When acetylated LDL was incubated with the same macrophage preparations, rates of synthesis averaged $7067 \pm 207 \mathrm{pmol}{ }^{14} \mathrm{C}$-cholesteryl oleate $\cdot \mathrm{mg}$ cell protein ${ }^{-1} \cdot 20 \mathrm{~h}^{-1}$. In incubations without added lipoproteins, synthesis rates averaged $86 \pm 27 \mathrm{pmol}$ ${ }^{14} \mathrm{C}$-cholesteryl oleate $\cdot \mathrm{mg}$ cell protein ${ }^{-1} \cdot 20 \mathrm{~h}^{-1}$.

We observed, however, that VLDL isolated from five Type 2 diabetic patients, almost one-third of the population studied, did stimulate more cholesteryl ester synthesis when incubated with macrophages. The clinical characteristics and parameters of glycaemic control and plasma lipid levels of this group of five diabetic patients (selected diabetic) are shown in Tables 1 and 2, respectively. There were no significant differences in the clinical characteristics of the subjects in each of the three groups (Table 1). The concentrations of fasting plasma glucose and $\mathrm{HbA}_{\mathrm{tC}}$ for both the diabetic and selected diabetic patients were significantly greater than those for the control group but were not statistically different between the diabetic and selected diabetic patients (Table 2). Plasma proteins were significantly more glycosylated in the diabetic $(p<0.001)$ and selected diabetic $(p<0.005)$ patients compared to control subjects, but the levels did not differ significantly between the two groups of diabetic patients. The extent of glycosylation of LDL did not differ significantly between control subjects and diabetic patients; however, LDL isolated from the selected diabetic patients was significantly more glycosylated than that isolated from control subjects $(p<0.01)$ but not from the other diabetic patients. There were no significant differences in the lipid profile of either group of diabetic patients compared to the control subjects or between the two groups of diabetic patients. The rate of cholesteryl ester synthesis in macrophages incubated with VLDL isolated from these selected patients was not significantly correlated with the patients' $\mathrm{HbA}_{1 \mathrm{C}}$ level $(p=0.052)$ or the extent of glycosylation of their LDL $(p=0.101)$ or plasma proteins $(p=0.310)$, although data from only five patients was used for this analysis. The rate of cholesteryl ester synthesis in macrophages incubated with LDL isolated from the selected diabetic patients did not differ significantly from that in cells incubated with LDL isolated from control subjects $(p=0.051)$. The correlation of the rate of cholesteryl ester synthesis in cells incubated with LDL isolated from selected diabetic patients with the extent of glycosylation of the LDL was not statistically significant $(p=0.071)$; however, again, data from only five patients was used for this analysis.

To determine if the increase in rate of cholesteryl ester synthesis in macrophages incubated with VLDL isolated from the selected diabetic patients resulted from alterations in VLDL composition, we determined the lipid and apoprotein composition of the VLDL isolated from each subject. The results of the analysis of VLDL lipid composition are shown in Table 3 . There were no significant differences in the free cholesterol or cholesteryl ester contents of VLDL isolated from these selected diabetic patients compared to control subjects or the remaining 
diabetic patients. The lipid composition of LDL isolated from both groups is also shown for reference. There were no significant differences in the lipid composition of LDL isolated from the selected diabetic patients compared to the two other groups; therefore, only the means for all diabetic patients are shown.

We also analysed the VLDL apoprotein composition to determine if this may have contributed to the altered interaction of VLDL from Type 2 diabetic patients with macrophages which resulted in increased rates of cholesteryl ester synthesis in the cells. These results are presented in Table 4. There were no significant differences in the mass of apoprotein $B$ relative to apoprotein $E$ in VLDL isolated from the three groups (Table 4). In addition, the proportion of apoprotein B relative to apoprotein $\mathrm{C}$ in the three groups was similar. However, the relative proportion of apoprotein C compared to apoprotein $\mathrm{E}$ was decreased in VLDL from the diabetic patients $(p<0.002$ vs control subjects). The mean apoprotein $\mathrm{C}$ to apoprotein $\mathrm{E}$ ratio value was further decreased in VLDL from the selected diabetic patients although this did not reach statistical significance either in relation to control subjects or to diabetic patients.

IEF was used to analyse VLDL apoprotein E and apoprotein $\mathrm{C}$ composition. This technique separates apoprotein $\mathrm{C}$ into the component apoprotein $\mathrm{C}$ isoforms. The distribution of apoprotein C isoforms in VLDL isolated from control subjects and diabetic patients is detailed in Table 5. There were no substantial differences in the percentage of apoprotein C-II in the VLDL isolated from each group. In contrast, there was an increase in the mean percentage of the densitometric area of VLDL apoprotein present as apoprotein C-I in VLDL isolated from the diabetic patients which was further increased in VLDL isolated from the group of selected diabetic patients ( $p<0.02$ vs control subjects). There was a concomitant decrease in the mean percentage of the densitometric area of VLDL apoprotein present as apoprotein C-III which was further decreased in VLDL isolated from the group of selected diabetic patients ( $p=0.059$ vs control subjects). There were no statistically significant differences in the proportion of the densitometric areas of apoprotein C-II relative to apoprotein C-I; however, the proportion of the densitometric area of apoprotein C-III relative to apoprotein C-I in VLDL from control subjects compared to VLDL from the selected diabetic patients was significantly decreased $(p<0.05)$. The relative proportions of the areas corresponding to apoprotein C-III compared to apoprotein C-II was similar for VLDL from the three groups. There were no differences in the proportions of the areas corresponding to apoprotein C-III-0, C-III-1, or C-III-2 among the three groups (data not shown).

A significant correlation was found between the extent of glycosylation of LDL isolated from the 16 diabetic patients and the extent of glycosylation of plasma proteins obtained from the same patients $(\mathrm{y}=1.41 \mathrm{x}+36.8$, $r=0.67, p<0.01)$. In addition, there was a significant correlation between $\mathrm{HbA}_{1 \mathrm{C}}$ concentration and the extent of glycosylation of both LDL $(y=7.72 x+36.6, r=0.66$, $p<0.05)$ and of plasma proteins $(\mathrm{y}=14.7 x+58.4$, $r=0.57, p<0.05)$.

\section{Discussion}

The results of the present study suggest that the metabolism by human macrophages of VLDL and LDL isolated from normolipidaemic patients with Type 2 diabetes who are in good glycaemic control is not significantly altered. There were no significant differences in the rates of cholesteryl ester synthesis in human macrophages incubated with VLDL isolated from the Type 2 diabetic patients compared with VLDL isolated from the non-diabetic, control subjects when the results from all the diabetic patients were analysed. However, VLDL isolated from almost one-third of the Type 2 diabetic patients studied did stimulate cholesteryl ester synthesis in human macrophages. There were no significant differences in the lipid composition of VLDL isolated from the diabetic patients compared to that for VLDL from control subjects or to that from the group of selected diabetic patients (Table 3), which could have contributed to the observed differences in cholesteryl ester synthesis. Previous studies indicated that VLDL isolated from another group of non-insulin-dependent diabetic patients which was enriched in cholesterol and triglycerides, was degraded more rapidly by thioglycolate elicited mouse peritoneal macrophages [17]. In the present study, VLDL from neither of the diabetic populations were enriched in triglycerides (Table 3). Additional studies reported a significant increase in the free and esterified cholesterol concentrations in VLDL isolated from a group of Type 2 diabetic patients in good glycaemic control [37] and therapeutic intervention may influence these levels [38]. This increase in cholesterol concentration has been localized to the smallest sized VLDL particles [39] but our studies did not permit us to evaluate this possibility.

There were substantial differences in the apoprotein composition of VLDL isolated from the Type 2 diabetic patients compared to control subjects. The percentage of VLDL apoprotein densitometric area present as apoprotein $\mathrm{E}$ was increased in the VLDL isolated from the diabetic patients whose VLDL did not stimulate cholesteryl ester synthesis in human macrophages and was further increased in the VLDL isolated from the selected diabetic patients (Table 4). Previous studies have reported an increase in plasma apoprotein E concentrations [39] and therapeutic intervention may decrease the apoprotein $E$ content of VLDL isolated from Type 2 diabetic patients [38]. Additional studies have found no changes in the amount of apoprotein $\mathrm{E}$ relative to apoprotein $\mathrm{B}$ in VLDL isolated from Type 2 diabetic patients although the apoprotein $\mathrm{E}$ concentration was decreased in proportion to triglyceride in VLDL isolated from these patients [40].

The apoprotein C composition of VLDL also differed significantly among the three groups of subjects (Table 5). Only a few detailed studies have been reported concerning the VLDL apoprotein C composition in diabetic patients $[38,41-45]$. The results of these studies are inconsistent but this may be related to the presence of hypertriglyceridaemia in the patient population or to differences in the techniques used to quantitate VLDL apoprotein composition.

The effects of alterations of VLDL total apoprotein composition or of apoprotein C composition on the inter- 
actions of the VLDL with non-hepatic lipoprotein receptors are unknown. The results of the present study do not permit us to speculate on the potential effects of the altered VLDL apoprotein composition on the interaction of these particles with macrophage lipoprotein receptors. Sufficient VLDL was not available to conduct the necessary lipoprotein binding and degradation studies. Clearly, however, VLDL isolated from the selected diabetic patients exhibited an altered apoprotein composition and may be considered atherogenic since these particles stimulated cholesteryl ester synthesis rates in human macrophages.

There were no significant differences in the rates of cholesteryl ester synthesis in human macrophages incubated with LDL isolated from the Type 2 diabetic patients compared to LDL isolated from control subjects when the results from all the diabetic patients were analysed. This is in direct contrast to similar experiments conducted with human macrophages which utilized LDL isolated from Type 1 diabetic patients [15]. The cause of this apparent discrepancy between the two studies is not known. There were no significant differences between the chemical composition of LDL isolated from either the Type 1 [15] or Type 2 (Table 3 ) diabetic patients and their corresponding control subjects. However, the magnitude of difference in the extent of glycosylation of LDL may be a contributing factor. The LDL isolated from the Type $1 \mathrm{pa}-$ tients was significantly more glycosylated than LDL from control subjects and the rate of cholesteryl ester synthesis in human macrophages was proportional to the extent of glycosylation of the LDL [14]. Only the LDL isolated from the selected group of Type 2 diabetic patients in the present study was significantly more glycosylated than LDL isolated from control subjects (Table 2). The rate of cholesteryl ester synthesis in macrophages incubated with this LDL was not proportional to the extent of glycosylation of the LDL ( $p=0.071)$; however, the number of subjects may have been too limited to assure statistical significance.

The extent of LDL glycosylation correlated well with commonly used indices of glycaemic control. There was a strong association between the extent of glycosylation of the LDL isolated from the selected diabetic patients and the increased rate of cholesteryl ester synthesis in macrophages incubated with these LDL. There was also a strong association between the rate of cholesteryl ester synthesis in macrophages incubated with VLDL isolated from the same patients and the extent of glycosylation of the LDL isolated from these patients. There was an even stronger association between the $\mathrm{HbA}_{1 \mathrm{C}}$ level in these patients and the rate of cholesteryl ester synthesis in macrophages incubated with their VLDL. These VLDL particles were also characterized by altered apoprotein compositions. These studies suggest that in normolipidaemic Type 2 diabetic patients, the level of glycaemic control may induce changes in lipoprotein composition which influence their interaction with macrophage lipoprotein receptors and alter cholesterol metabolism in these cells. This altered lipoprotein-macrophage interaction may contribute to the increased prevalence of atherosclerosis in diabetic patients.
Acknowledgements. The authors wish to thank Drs. J.A.Colwell and R. K. Mayfield for their assistance in patient recruitment and for permission to study patients under their care. We acknowledge Dr. H.C. Stevenson of the National Cancer Institute, Frederick, Maryland, USA for graciously contributing the human monocytes used in these studies. We also acknowledge the cooperation and assistance of the staff of the General Clinical Research Center, Medical University of South Carolina, Charleston and the Special Diagnostic and Treatment Unit, Veterans Administration Medical Center, Charleston, SC, USA. Expert technical assistance was provided by Ms. G. Waldrop and Mr. L. Long. Secretarial assistance was provided by Mrs. M.Blackburn. This work was supported by the Research Service of the Veterans Administration and by the National Institutes of Health Grant HL 30929.

\section{References}

1. West KM (1982) Hyperglycemia as a cause of long-term complications. In: Keen H, Jarrett RJ (eds) Complications of diabetes. Edward Arnold, London, pp 13-18

2. Garcia MJ, McNamara PM, Gordon T, Kannel WB (1974) Morbidity and mortality in diabetics in the Framingham population. Diabetes 23: 105-111

3. Chait A, Bierman EL, Brunzell JD (1985) Diabetic macroangiopathy. In: Albert KGMM, Krall LP (eds) The diabetes annual/1. Elsevier, New York, pp 323-348

4. Lopes-Virella MF, Sherer GK, Lees AM, Wohltmann H, Mayfield R, Sagel J, LeRoy EC, Colwell JA (1982) Surface binding, internalization and degradation by cultured human fibroblasts of low density lipoproteins isolated from Type 1 (insulin-dependent) diabetic patients: changes with metabolic control. Diabetologia 22: 430-436

5. Kraemer FB, Chen Y-DI, Cheung RMC, Reaven GM (1982) Are the binding and degradation of low density lipoprotein altered in Type 2 (non-insulin-dependent) diabetes mellitus? Diabetologia 23: 28-33

6. Hiramatsu K, Bierman EL, Chait A (1985) Metabolism of lowdensity lipoprotein from patients with diabetic hypertriglyceridemia by cultured human skin fibroblasts. Diabetes 34: 8-14

7. Gonen B, Baenziger J, Schonfeld G, Jacobson D, Farrar P (1981) Nonenzymatic glycosylation of low-density lipoprotein in vitro. Diabetes $30: 875-878$

8. Witztum JL, Mahoney EM, Branks MJ, Fisher M, Elam R, Steinberg D (1982) Nonenzymatic glucosylation of low-density lipoprotein alters its biologic activity. Diabetes 31: 283-291

9. Sasaki J, Cottam GL (1982) Glycosylation of LDL decreases its ability to interact with high affinity receptors of human fibroblasts in vitro and decreases its clearance from rabbit plasma in vivo. Biochim Biophys Acta 713: 199-207

10. Schleicher E, Olgemoller B, Schon J, Durst T, Wieland OH (1985) Limited nonenzymatic glucosylation of low-density lipoprotein does not alter its catabolism in tissue culture. Biochim Biophys Acta 846: 226-233

11. Steinbrecher UP, Witztum JL (1984) Glucosylation of low-density lipoprotein to an extent comparable to that seen in diabetes slows their catabolism. Diabetes 33: 130-134

12. Lorenzi M, Cagliero E, Markey B, Henriksen T, Witztum JL, Sampietro T (1984) Interaction of human endothelial cells with elevated glucose concentrations and native and glycosylated low density lipoproteins. Diabetologia 26:218-222

13. Lamamoto M, Ranganathan S, Kottke BA (1986) Metabolism of glycosylated very low-density lipoprotein in human skin fibroblasts. Biochim Biophys Acta 875: 410-413

14. Lopes-Virella MF, Klein RL, Lyons TJ, Stevenson HC, Witztum JL (1988) Glycation of low-density lipoproteins enhances cholesteryl ester synthesis in human monocyte macrophages. Diabetes 37: 550-557

15. Lyons TJ, Klein RL, Baynes JW, Stevenson HC, Lopes-Virella MF (1987) Stimulation of cholesteryl ester synthesis in human 
monocyte-derived macrophages by low-density lipoproteins from Type 1 (insulin-dependent) diabetic subjects: the influence of non-enzymatic glycosylation of low-density lipoproteins. Diabetologia 30: $916-923$

16. Klein RL, Lyons TJ, Lopes-Virella MF (1989) Interaction of VLDL isolated from Type 1 (insulin-dependent) diabetic subjects with human monocyte derived macrophages. Metabolism 38: $1108-1114$

17. Kraemer FB, Chen Y-DI, Lopez RD, Reaven GM (1985) Effects of non-insulin-dependent diabetes mellitus on the uptake of very low density lipoproteins by thioglycolate-elicited mouse peritoneal macrophages. J Clin Endocrinol Metab 61: 335-342

18. National Diabetes Data Group (1979) Classification and diagnosis of diabetes mellitus and other categories of glucose intolerance. Diabetes 28: 1039-1057

19. Stevenson HC, Beman JA, Oldham RK (1983) Design of a cancer immunology cytapheresis unit. Plasma Therapy 4: 57-63

20. Stevenson HC (1985) Separation of mononuclear leukocyte subsets by countercurrent centrifugation elutriation. In: Gosabato $\mathrm{G}$, Langone $\mathrm{T}$, von Vunakis $\mathrm{H}$ (eds) Methods in enzymology: immunochemical techniques, part G. Academic Press, New York, pp 242-249

21. Stevenson HC, Katz P, Wright DG, Contreras TJ, Jemionek JF, Hartwig VM, Flor WJ, Fauci AS (1981) Human blood monocytes: characterization of the negatively selected human monocyte and their suspension cell culture derivatives. Scand J Immunol 14: 243-256

22. Folch J, Lees M, Stanley GHS (1957) A simple method for the isolation and purification of total lipids from animal tissues. $J$ Biol Chem 226: 497-509

23. Ishikawa TT, McGee Y, Morrison JA, Glueck CJ (1974) Quantitative analyses of cholesterol in 5 to $20 \mu \mathrm{l}$ of plasma. $J$ Lipid Res 15: 286-291

24. Manual of Lipid Operations (1974) Lipid Research Clinics Program, Vol.1. Lipid and lipoprotein analysis, Dept. of Health, Education and Welfare, Publ. No. (NIH) 75-628, pp 9-37

25. Bartlett GR (1959) Phosphorus assay in column chromatography. J Biol Chem 234: 466-468

26. Markwell MAK, Haas SM, Bieber LL, Tolbert NE (1978) A modification of the Lowry procedure to simplify protein determination in membrane and lipoprotein samples. Anal Biochem 87: 206-211

27. Lopes-Virella MF, Virella G, Evans G, Malenkas SB, Colwell JA (1980) Immunonephelometric assay of human apolipoprotein A-I. Clin Chem 26: 1205-1208

28. Warnick GR, Mayfield C, Albers JJ, Hazzard WR (1979) Gel isolectric focusing method for specific diagnosis of familial hyperlipoproteinemia Type 3. Clin Chem 25: 279-284

29. Reisner AH, Nemes P, Bucholtz C (1975) The use of Coomassie brilliant blue G-250 perchloric acid solution for staining in electrophoresis and isolectric focusing on polyacrylamide gels. Anal Biochem 64: 509-516

30. Holbrook IB, Leaver AG (1976) A procedure to increase the sensitivity of staining by Coomassie brilliant blue G-250 perchloric acid solution. Anal Biochem 75: 634-636

31. Catapano AL (1980) The distribution of apo C-II and apo C-III in very low density lipoproteins of normal and type IV subjects. Atherosclerosis 35: 419-424

32. Kashyap ML, Hynd BA, Robinson K, Gartside PS (1981) Abnormal preponderance of sialylated apolipoprotein C-II in triglyceride-rich lipoproteins in type $\mathrm{V}$ hyperlipoproteinemia. Metabolism 30: 111-118
33. Lyons TJ, Baynes JW, Patrick JS, Colwell JA, Lopes-Virella MF (1986) Glycosylation of low density lipoprotein in patients with Type 1 (insulin-dependent) diabetes: correlations with other parameters of glycaemic control. Diabetologia 29: 685-689

34. Kadish AH, Little RL, Steinberg JC (1986) A new and rapid method for the determination of glucose by measurement of rate of oxygen consumption. Clin Chem 14: 116-131

35. Spicer KN, Allen RC, Buse MG (1978) A simplified assay of hemoglobin $A_{1 C}$ in diabetic patients using isoelectric focusing and quantitative microdensitometry. Diabetes 27: 384 388

36. Lopes-Virella MF, Stone P, Ellis S, Colwell JA (1977) Cholesterol determination in high density lipoproteins separated by three different methods. Clin Chem 23: 882-884

37. Weisweiler P, Schwandt P (1987) Type 1 (insulin-dependent) versus Type 2 (non-insulin-dependent) diabetes mellitus: characterization of serum lipoprotein alterations. Eur J Clin Invest 17: $87-91$

38. Weisweiler P, Drosner M, Schwandt P (1982) Dietary effects on very low-density lipoproteins in Type 2 (non-insulin-dependent) diabetes mellitus. Diabetologia 23: 101-103

39. Kasama T, Yoshino G, Iwatani I, Iwai M, Hatanaka H, Kazumi T, Oimomi M, Baba S (1987) Increased cholesterol concentration in intermediate density lipoprotein fraction of normolipidemic non-insulin-dependent diabetics. Atherosclerosis 63: 263-266

40. Taskinen MR, Beltz WF, Harper I, Fields RM, Schonfeld G, Grundy SM, Howard BV (1986) The effects of non-insulin-dependent diabetes mellitus on VLDL triglyceride and VLDL apo B metabolism: studies before and after sulfonylurea therapy. Diabetes 35: 1268-1277

41. Pagnan A, Padovan D, Guarini P, Teodoro N, Zanetti G (1980) Serum lipids and apoprotein composition (\%) of the very low density lipoprotein (VLDL) fraction in two groups of diabetic patients: effects of oral as compared to insulin therapy. Acta Diabetol Lat 17:225-228

42. Gabor J, Spain M, Kalant N (1980) Composition of serum verylow-density and high-density lipoproteins in diabetes. Clin Chem 2: $1261-1265$

43. Stalenhoef AFH, Demacker PNM, Lutterman JA, van't Laar A (1982) Apolipoprotein $\mathrm{C}$ in Type 2 (non-insulin-dependent) diabetic patients with hypertriglyceridaemia. Diabetologia 22: 489-491

44. Shoukry MI (1986) Apo C-III levels in Type IV hyperlipoproteinemia associated with non-insulin dependent diabetes. Indian J Med Res 84: 297-300

45. Pan X-R, Cheung MC, Walden CE, Hu S-X, Bierman EL, Albers JJ (1986) Abnormal composition of apoproteins C-I, $\mathrm{C}$-II, and C-III in plasma and very-low-density lipoproteins of non-insulin-dependent diabetic Chinese. Clin Chem 32: $1914-1920$

Received: 21 July 1989

and in revised form: 1 December 1989

Dr. R.L. Klein

Research Service (151)

Veterans Administration Medical Center

109 Bee Street

Charleston, SC 29403

USA 